One of the main purposes of the address is to show that from the map of the distribution of culture-facts, the investigator can deduce the cradle of the various cultures and the order of their evolution. This principle, long used by the botanist and biologist, is of great value to the anthropologist, sociologist and philologist. The distributions of man, of various industries and populations, of languages, etc., belong to the field of the geographer. A lengthy study of such distributions leads to views often much at variance with those accepted as orthodox. Some examples discussed are the cradle-land of man, the differentiation of the races, the inaccuracy of the terms 'Caucasian' and 'Mongolian', the spread of cultures from Asia into the Pacific, and the probable cradle of civilization. In many of these problems the implications of the isopleths have been ignored by most researchers.

It is suggested that a new term is needed for groups which are linked by culture, but are not racial units. An extension of the use of the word 'cult' is suggested. Thus there is no Jewish race in Europe, or French race in Canada; but it is logical to talk of a Jewish or French 'cult'. Race should denote 'breed', and is purely a biological concept. The problem of the Jews and of the Aryans is used to illustrate a glaring example of dangerous ignorance on the part of powerful political groups. A new technique of approaching linguistic relationships-based on distributions-is discussed. It seems to offer clues as to the relationships between, and the origins of, Aryan, Basque, Altaic, and other linguistic groups. Prof. Griffith Taylor believes that the Aryan languages originated near the Caspian. He suggests that the isopleths support the view that the Nordic race originally spoke Finn or some allied nonAryan language.

Geographers may be classified in three groups: theocratic (that is, teleological), environmental or possibilist. A belief in environmental control, to which the name "Stop-and-go Determinism" has been given, is favoured. It is opposed to the orthodox views of geographic philosophy.

A drastic revision of the programme for a general cultural education is required, especially in the Dominions. Educators must abandon the technique of Augustine of Canterbury for that of Aristotle. The latter tried (in a living language) to put the youth of Greece en rapport with the vital problems of the day. He did not insist on their spending years trying to learn the long-dead language of Tutankhamen.

It would seem desirable to swing the attention of youth for a generation or two from a study of classics or of the problems of physical science to the more difficult and dangerous problems of social science. There is no risk to-day, though there was in the past, in stating that the earth is a globe, revolves around the sun, and is of infinitely small importance in the cosmos. But there is grave danger in many circles in stating the truth about Communism, Socialism, Judaism, Nordicism, and many other -isms which conflict with established or dictatorial interests. These creeds are cultural facts, which can be more readily understood if tackled in a graphic manner. It is no quibble to say that they are to-day more vital to the man of culture, that is, with a wellrounded education, than is the well-recognized and valuable culture based on art, music, or classics. Thus the geographer whose interests lie not only in the economic but also in the cultural field can feel that he is working right on the battlefront in man's progress towards a higher type of civilization.

Eighteen ecological diagrams form an essential feature of the address.

\section{Scope and Method of Economics}

$7 \mathrm{HE}$ object of the presidential address by Mr. R. F. Harrod to Section F (Economics) on method is threefold : (1) An attempt is made to show the kind of knowledge on which the practical recommendations, which economists have been in the habit of giving with a considerable degree of assurance, are grounded. (2) An attempt is made to define precisely the empirical basis of the general laws which constitute traditional economic theory. (3) Attention is given to the new ground over which contemporary theory, more tentative and more empirical, is striving to advance.

The recommendations do not issue from a set of 'laws' relating to the causal sequence of events. The scientific groundwork of these recommendations is a systematic classification of different kinds of economic activity and a simultaneous conspectus of the system as a whole. For example, the condemnation of protection is not based on precise knowledge of the sum of consequences likely to result from it; but when we have made a systematic classification of the purposes of economic effort and grasped the mode of operation of the system of a whole, we see that protection fails to take account of this, implicitly assumes a different working of the system and, save in exceptional circumstances, produces a net residue of frustation.

The economist's criterion of the good as that which is preferred is defined, and it is shown that it may be validly employed whatever the moral or political objectives of the society may be. The economist's criterion is free from 
moral or political bias, and it has to be employed even if the economist is asked to advise subject to some stated political objective, such as national self-sufficiency.

In addition to the system of prescriptions, traditional economics has provided a body of general laws relating to the sequence of events. These have been largely deductive, because they spring from a single simple principle, which has an empirical basis, but one derived from an immensely wide human experience, namely, the law of demand or the law of diminishing utility. This is almost axiomatic, and further investigations are unlikely to reinforce the authority it already has. By the aid of it and of its corollaries, it is possible to derive a theory of supply and demand, by which the effect of specified changes on the course of prices, wages, employment, etc., may in principle be determined. But this law and its corollaries are of very wide generality and consequently are of little use for prediction in any particular circumstances.

To have greater predictory power in this field, it would be necessary to be able to state the laws governing the demand for particular commodities, etc., in quantitative terms. Owing to the plurality of causes, it is extremely difficult to derive such laws from the data of observation. The quantitative laws would certainly be far more conjectural than the general qualitative results derived from the demand axiom. Interesting attempts have been made along these lines. But it is probable that the future of quantitative empirical economics lies elsewhere. Indeed the success of deductive reasoning up to a certain point has probably caused an excessive concentration of effort on this branch of the subject.

The wealth of recommendation, which has characterized past economics, may be reconciled with its paucity of predictory power, when it is appreciated that the power does not rest on the few general causal laws which we have, but on classificatory and survey work.

Contemporary study is seeking new approaches to the establishment of general causal laws, outside the ambit of the traditional laws of demand and supply. It is not yet certain whether greater success is likely to be obtained by the hypotheticaldeductive method, which must depend on suitable data being thrown up by the facts of the working world to take the place of the crucial experiment, or by a more radically empirical method, which seeks by constant study and re-classification of the facts to make them speak for themselves and suggest new laws.

In one field at least Mr. Harrod hopes for a further successful outgrowth of deductive theory. The laws of demand and supply, already referred to, which are sometimes known as 'static theory', may be compared with the laws of statics relating to bodies at rest. It should be possible to develop a system of laws, which by analogy may be called dynamic theory, relating to the behaviour of a system when the fundamental magnitudes, population, capital, etc., are increasing (or decreasing). Mr. Harrod suspects that we are on the verge of formulating one or two simple axioms, based on very wide experience and having almost as great an authority as the law of demand in static economics, from which a quite complicated set of laws relating to a system in motion may be derived. Such an axiom may be that people save a larger amount if they have a larger income. Since our society is in fact growing and not stationary, the hypotheses which theorists will be disposed to make in this department will be subject to easier verification than those of static theory.

This is, however, but one out of many possible lines of advance. A greater tendency towards the empirical may safely be predicted. Empirical work in economics is exceedingly laborious, and can only flourish if there is ample endowment for full-time research workers. The branch of statistical theory of especial use to empirical economists is at present displaying a welcome vitality.

Economists should be keenly alive to the findings of workers-sociologists, anthropologists, etc., on the periphery of their subject. But the suggestion recently put forward by one or two eminent persons that economics is in a parlous state requiring salvage by workers in sister subjeets is rejected with contempt. Of all the social studies, economics has been most successful in attaining valid general laws of interest and authority, and it is at the moment in a condition in which an advance over a wide front may reasonably be expected.

\section{Changing Outlook of Engineering Science}

IN Section G (Engineering), seeking a topic of $I_{\text {concern to both practising and academic members }}$ of his audience, the president, Prof. R. V. Southwell, undertakes a general stocktaking-to view the trend of engineering science regarded both as an art and as a field for study, teaching and research. He divides his presidential address into three main sections, dealing (1) with policy in regard to the teaching of engineering science, (2) with policy in regard to engineering research, and (3) with 'foreign policy' - the relation of the engineer to the community ; its keynote throughout being that in the changing circumstances of to-day engineers, whether practical or academic, must frame their policies in collaboration, not 